\title{
Semaphorin 3C Released from a Biocompatible Hydrogel Guides and Promotes Axonal Growth of Rodent and Human Dopaminergic Neurons
}

\author{
Oscar A. Carballo-Molina, BS,,2 Andrea Sánchez-Navarro, BS,1,2 Adolfo López-Ornelas, MD, PhD,,2 \\ Rolando Lara-Rodarte, BS, ${ }^{1,2}$ Patricia Salazar, MS, ${ }^{3}$ Aurelio Campos-Romo, MD, PhD, \\ Verónica Ramos-Mejía, $\mathrm{PhD}^{3}$, and Iván Velasco, $\mathrm{PhD}^{1,2}$
}

Cell therapy in experimental models of Parkinson's disease replaces the lost dopamine neurons (DAN), but we still need improved methods to guide dopaminergic axons (DAx) of grafted neurons to make proper connections. The protein Semaphorin 3C (Sema3C) attracts DAN axons and enhances their growth. In this work, we show that the hydrogel PuraMatrix, a self-assembling peptide-based matrix, incorporates Sema3C and releases it steadily during 4 weeks. We also tested if hydrogel-delivered Sema3C attracts DAx using a system of rat midbrain explants embedded in collagen gels. We show that Sema3C released by this hydrogel attracts DAx, in a similar way to pretectum, which is known to attract growing DAN axons. We assessed the effect of Sema3C on the growth of DAx using microfluidic devices. DAN from rat midbrain or those differentiated from human embryonic stem cells showed enhanced axonal extension when exposed to hydrogel-released Sema3C, similar to soluble Sema3C. Notably, DAN of human origin express the cognate Sema3C receptors, Neuropilin1 and Neuropilin2. These results show that PuraMatrix is able to incorporate and release Sema3C, and such delivery guides and promotes the axonal growth of DAN. This biocompatible hydrogel might be useful as a Sema3C carrier for in vivo studies in parkinsonian animal models.

\section{Introduction}

A XONS GROW WITH spatiotemporal specificity through the response to different cues during embryonic stages. Such growth is directed by the expression of ligands and their cognate receptors. The large family of Semaphorins (Sema) includes both soluble and membrane-bound proteins that mediate axonal guidance through Rho-related $G$ proteins. ${ }^{1,2}$ Class 3 Sema (Sema 3) are guide molecules well conserved in several species. ${ }^{3}$ Sema3A was initially reported as Collapsin, as exposure of sensory neuron explants of the chick dorsal root ganglia to this protein produced growth cone collapse. ${ }^{4}$

Although initially characterized as inhibitors of axonal growth, it was later discovered that Sema3 can induce either repulsive or attractive effects depending on the cellular context. ${ }^{1}$ Sema3A on cortical axons ${ }^{5}$ or Sema3E on retinal ganglion cells ${ }^{6}$ produced repulsive effects. On the contrary, Semaphorin 3C (Sema3C) secreted by a transient neuronal population exerted an attractive influence on crossing callosal axons during development. ${ }^{7}$ Exposure of developing mouse hippocampal subicular neurons to Sema3E promotes and attracts the axonal growth, an effect mediated by Neuropilin (NRP) $1 .^{8}$

Several Sema proteins influence the growth of mesencephalic dopaminergic axons (DAx) during development: Sema3A, ${ }^{9-11}$ Sema3C, ${ }^{10,11}$ Sema3F, ${ }^{9,10}$ Slit-2, ${ }^{12-15}$ and Netrin- $1^{12,14-16}$ are all implicated in the guidance of DAx to reach the striatal area. Growing DAx respond differentially to Sema3 signaling: Sema3F is repulsive for DAx emanating from mesencephalic explants embedded in collagen gells. ${ }^{10}$ In contrast, Sema3C and Sema3A increase the axonal growth of DAx, whereas Sema3C also attracts DAx of mesencephalic

\footnotetext{
${ }^{1}$ Instituto de Fisiología Celular-Neurociencias, Universidad Nacional Autónoma de México, México, D.F., México.

${ }^{2}$ Laboratorio de Reprogramación Celular IFC/UNAM en el Instituto Nacional de Neurología y Neurocirugía "Manuel Velasco Suárez," México, D.F., México.

${ }^{3}$ GENYO: Centre for Genomics and Oncological Research Pfizer-University of Granada-Junta de Andalucía, PTS Granada, Spain.

${ }^{4}$ Unidad Periférica de Neurociencias Facultad de Medicina-UNAM en el Instituto Nacional de Neurología y Neurocirugía "Manuel Velasco Suárez," México, D.F., México.

(C) Oscar A. Carballo-Molina, et al., 2016; published by Mary Ann Liebert, Inc. This Open Access article is distributed under the terms of the Creative Commons Attribution Noncommercial License (http://creativecommons.org/licenses/by-nc/4.0/) which permits any noncommercial use, distribution, and reproduction in any medium, provided the original author(s) and the source are credited.
} 
neurons and those derived in vitro from mouse embryonic stem (ES) cells. ${ }^{11}$ Neutralizing antibodies for the Sema3C receptors NRP1 and NRP2 block Sema3C effects on rodent DAx. ${ }^{11}$

The low ability of axon regeneration in the adult central nervous system (CNS) has been widely documented and is mainly due to the lack of signals present during development and to the expression of inhibitory molecules by reactive glial cells. ${ }^{17-19}$ These impediments become relevant when axonal regeneration in the CNS is needed to repair the damaged or diseased brain. In Parkinson's disease (PD), DAx that form the nigrostriatal pathway are lost, secondary to the death of dopamine neurons (DAN) in the substantia nigra (SN). Grafting of DAN in the striatum, the region originally innervated by DAx, causes behavioral recovery in adult parkinsonian rats. ${ }^{20-25}$ However, this strategy applied to PD patients did not cause consistent recovery. 26,27

In contrast, when DAN are grafted in the $\mathrm{SN}$, they are unable to project their axons to the striatum ${ }^{28-30}$ probably due to the adverse environment for axonal growth. Enhancing and directing DAx growth is an appealing idea to be tested when grafting neurons in PD models. In a rat model of PD, we previously demonstrated that transfected HEK293 cells could release Sema3C along an artificial trajectory between the $\mathrm{SN}$ and the striatum, promoting the DAx growth of neurons grafted in the $\mathrm{SN}$, resulting in behavioral improvement. ${ }^{25}$

The use of biomaterial scaffolds might constitute an ideal strategy to replace transfected cells for delivery of Sema3C to the brain. Hydrogels are polymers that incorporate large quantities of water in their structure ${ }^{31,32}$ and gels in response to several physiological conditions, such as temperature ${ }^{33,34}$ or osmolarity. ${ }^{35,36}$ Recent studies have shown the usefulness of hydrogels as drug carries due to their ability for in vivo or in vitro release (reviewed in Carballo-Molina and Velasco ${ }^{37}$ ). For example, neurotrophic factors such as glial cell-derived neurotrophic factor (GDNF), ${ }^{38}$ brain-derived neurotrophic factor (BDNF) ${ }^{39}$ or ciliary neurotrophic factor ${ }^{40}$ can be incorporated to the hydrogel and then released.

Hydrogels are also a good substrate for neural cells, allowing their survival, growth and proliferation (reviewed in Carballo-Molina and Velasco ${ }^{37}$ ). Neural stem cells can proliferate and differentiate when embedded in hydrogels in vitro ${ }^{41,42}$ and in vivo. ${ }^{43}$ Some researchers have investigated the use of hydrogels as cell carriers of rat neurons ${ }^{44}$ and human neural progenitor cells. ${ }^{45}$ Several groups have reported that the implantation of hydrogels to rodent and primate brains does not cause tissue rejection and promotes axonal growth (reviewed in Carballo-Molina and Ve$\operatorname{lasco}^{37}$ ).

The hydrogel PuraMatrix is a synthetic molecule constituted by self-assembling peptides with the sequence argininealanine-aspartate-alanine repeated 16 times (RADA16). ${ }^{46}$ This hydrogel promoted recovery in a hamster model of blindness when implanted in the brain ${ }^{36}$ and helped recover from cortical lesions, ${ }^{43,47}$ mainly by allowing axonal growth and the formation of synapses in vitro. ${ }^{46}$ Furthermore, PuraMatrix can incorporate different proteins into its structure and release them in vitro. ${ }^{35,48}$ In this study, we evaluated if PuraMatrix can release Sema3C and guide/promote DAx growth. We show that PuraMatrix-embedded Sema3C is stably released and that such delivery causes attraction of DAx from midbrain DAN.
Quantification of the growth of DAx of rat and human origin showed that Sema3C released by this hydrogel caused significant larger axons, compared to controls.

\section{Materials and Methods}

\section{Conjugation of proteins to hydrogel and release assays}

We used the RADA16 BD PuraMatrix hydrogel (1\% w/v solution) based on self-assembling peptides. The hydrogel was diluted with sterile water to obtain a $0.15 \%$ w/v final concentration as recommended by the manufacturer. The hydrogel was combined with recombinant human Sema3C peptide (Abcam) and incubated at $37^{\circ} \mathrm{C}$ in a sterile saline solution for 28 days; an aliquot of the solution was recovered and the same volume was added every day. The experiment was repeated five times for each concentration. Sema3C was mixed with this hydrogel solution previous to the gelling process, which was triggered by adding saline solution $(0.9 \% \mathrm{NaCl}) .{ }^{49}$ To measure the release of Sema3C conjugated at 5 and $10 \mu \mathrm{g} / \mathrm{mL}$ with hydrogel, an ELISA was performed, according to the manufacturer's protocol (Cloud-Clone Corp).

\section{Animals}

Adult Wistar rats and embryos at 14 days of gestational age (E14) were used. The animals were maintained and handled in accordance with the local animal care and use committee and complied local (NOM-062-ZOO-1999) and international guidelines (Animal Welfare Assurance A5281-01). Rats were housed with a 12-h light-12-h dark cycle at room temperature (RT, $22^{\circ} \mathrm{C} \pm 2^{\circ} \mathrm{C}$ ). Water and food were freely available. Animals were euthanized. All efforts were made to minimize the number of animals used and to avoid pain or discomfort.

\section{Collagen extraction from rat tails}

The collagen extraction procedure was made as reported previously. ${ }^{50}$ Four adult frozen rat tails were rinsed with $70 \%$ ethanol. Tendons were extracted using sterile tweezers and rinsed with $70 \%$ ethanol. We obtained $2 \mathrm{~g}$ of tendons that were cut into $0.5 \mathrm{~cm}$ fragments. The dry tendons were transferred to $60 \mathrm{~mL}$ of ice-cold $0.1 \%$ acetic acid solution. Tendons were stirred for $20 \mathrm{~h}$ at $4^{\circ} \mathrm{C}$. The solution was diluted with $80 \mathrm{~mL}$ of sterile water and centrifuged at $9000 \mathrm{rpm}$ for $30 \mathrm{~min}$ at $4^{\circ} \mathrm{C}$. This solution was used to prepare collagen gels.

\section{Assays of explants in collagen gels to measure axonal attraction}

Ventral midbrain $(\mathrm{Mb})$, isthmic region (Ist), and pretectum (PT) explants were obtained from E14 embryos as described ${ }^{10}$ and were maintained in Krebs solution. Ventral Mb explants were embedded in a collagen matrix by mixing $300 \mu \mathrm{L}$ of $\mathrm{N} 2$ medium (DMEM/F12 1:1, supplemented with $25 \mu \mathrm{g} / \mathrm{L}$ of human insulin, $30 \mathrm{nM}$ sodium selenite, $100 \mu \mathrm{M}$ putrescine, $20 \mathrm{nM}$ progesterone, and $100 \mathrm{mg} / \mathrm{L}$ of apotransferrin) with $100 \mu \mathrm{L}$ of collagen solution, $10 \mu \mathrm{L}$ of $1.537 \mathrm{M} \mathrm{NaCl}$ solution (final concentration of $36.6 \mathrm{mM}$ ), and $10 \mu \mathrm{L}$ of $0.89 \mathrm{M}$ of $\mathrm{NaHCO}_{3}$ (final concentration of $21.2 \mathrm{mM}$ ); this mixture was maintained on ice before the gelling process. The Mb explants were embedded together with PT $(n=23)$ or with Ist $(n=17)$ explants, on four-well dishes (Nunc), and let to polymerize at $37^{\circ} \mathrm{C}$ for $1 \mathrm{~h}$. Special care was taken to keep a distance of 500 
$1000 \mu \mathrm{m}$ between explants before adding another layer of collagen and let to polymerize for an additional hour. Finally, $700 \mu \mathrm{L}$ of $\mathrm{N} 2$ medium was added.

For hydrogel experiments, a drop of PuraMatrix coupled to either Sema3C $(n=21)$ or gelatin from pig skin coupled to Oregon Green ${ }^{\circledR} 488$ (Molecular Probes) as a control protein (Cp), since this protein has a similar weight and charge to Sema3C $(n=11)$, both at $200 \mu \mathrm{g} / \mathrm{mL}$, was jellified for $1 \mathrm{~h}$ by adding medium at RT. A layer of collagen was added and immediately the $\mathrm{Mb}$ explants were introduced. After $1 \mathrm{~h}$ at $37^{\circ} \mathrm{C}$, an additional layer of collagen was added and let to polymerize for $1 \mathrm{~h}$, and finally, $700 \mu \mathrm{L}$ of $\mathrm{N} 2$ medium was added. Explants were cultured for 5 days without medium change.

To determine the attraction/repulsion effects on $\mathrm{Mb}$ explants, the $\mathrm{TH}+$ axon length was measured with ImageJ software (National Institutes of Health) using NeuronJ plugin. ${ }^{51}$ The $\mathrm{Mb}$ explants were divided into two areas, proximal (P) or distal (D) (as indicated in the scheme of Fig. 2A). In cases where explants extended many axons, only the 10 largest were considered; when axons were fewer than 10, all axons were measured. The average axonal length for $\mathrm{D}$ and $\mathrm{P}$ sides was obtained to calculate the P/D ratio. When the value was greater than 1.0, it was considered an attractive effect; values smaller than 1.0 were considered repulsive. ${ }^{52}$ When the $\mathrm{Mb}$ explant does not present axonal growth, a zero value was registered. One methodological problem we encountered in the hydrogel groups was that the gel often fragmented when collagen was placed on top. We discarded experiments where many pieces of hydrogel were present.

\section{Dopaminergic differentiation of H9 human ES cells}

The ES cell line H9 was used after lentiviral transduction for GFP expression as reported. ${ }^{53}$ Dopaminergic neuron differentiation was made with the dual-SMAD inhibition and floor plate induction. ${ }^{54}$ Briefly, H9 cells were plated on Matrigel (BD), grown for 11 days in a knockout serum replacement medium (KSR) containing knockout DMEM, 15\% serum replacement, $2 \mathrm{mM}$ GlutaMAX, $1 \mathrm{X}$ nonessential amino acids, and $10 \mu \mathrm{M} \beta$-mercaptoethanol. Cultures were exposed to LDN193189 (100 nM, Stemgent; days 0-11), SB431542 (10 $\mu \mathrm{M}$, Tocris; days 0-5), the sonic agonists SAG ( $1 \mu \mathrm{M}$, Sigma; days $1-9)$ and Purmorphamine $(2 \mu \mathrm{M}$, Stemgent; days 1-9), FGF8 (100 ng/mL, Prepotech; days 1-7) and CHIR99021 (3 $\mu \mathrm{M}$, Stemgent; days 3-13). The KSR medium was gradually shifted to N2 medium starting on day 5. On day 11 , the medium was changed to the Neurobasal medium with B27 supplement (NB/B27; Invitrogen) supplemented with BDNF $(20 \mathrm{ng} / \mathrm{mL}$, Prepotech), ascorbic acid $(0.2 \mathrm{mM}$, Sigma), GDNF (20 ng/mL, Prepotech), TGF 33 ( $1 \mathrm{ng} / \mathrm{mL}$, Prepotech), dibutyryl cAMP (0.5 mM; Sigma), and DAPT $(10 \mu \mathrm{M}$; Sigma) for 10 days. On day 21, cells were dissociated using TrypLE Express (Life Technologies) and replated on microfluidic devices.

\section{Axonal growth chambers}

Polydimethylsiloxane microfluidic devices were purchased from Xona Microfluidics (Standard Neuron Device Cat.No: SND900) and were used according to the manufacturer's protocol. Briefly, they were attached by pressure to a coverslip precoated with poly-L-ornithine $(15 \mu \mathrm{g} / \mathrm{mL}) /$ laminin $(1 \mu \mathrm{g} / \mathrm{mL}) /$ fibronectin $(2 \mu \mathrm{g} / \mathrm{mL})$. The ventral $\mathrm{Mb}$ region was dissected from E14 rat embryos in Krebs solution and dissociated with TrypLE Express (Gibco) to obtain DAN. Cells were plated $(250,000$ cells $/ 5 \mu \mathrm{L})$ in the cell compartment (Fig. 3A). After $10 \mathrm{~min}, 100 \mu \mathrm{L}$ of N2 medium was added. The other side of the chamber was filled with $200 \mu \mathrm{L}$ of $\mathrm{N} 2$ medium alone (control) or with $20 \mu \mathrm{g} / \mathrm{mL}$ Sema3C. For hydrogel experiments, $100 \mu \mathrm{L}$ of the medium was first added in one supply well in the opposite compartment where cells were plated (Fig. 3A), then $3.5 \mu \mathrm{L}$ of the hydrogel containing $200 \mu \mathrm{g} / \mathrm{mL}$ of Sema3C or $\mathrm{Cp}$ and $100 \mu \mathrm{L}$ of medium were added. The cultures were maintained at $37^{\circ} \mathrm{C}$ in humidified $5 \% \mathrm{CO}_{2} / 95 \%$ air for 5 days. Each chamber contains a variable number of axons, although the cells were plated at the same initial density; the total numbers of axons measured were as follows: medium alone $(n=48)$, medium plus soluble Sema3C $(n=59)$, hydrogel with Cp $(n=90)$, and hydrogel coupled to Sema3C $(n=92)$. Axonal growth in the microgrooves of the chambers was measured by ImageJ software using NeuronJ plugin. ${ }^{51}$ We decided to use this software because it allows the measurement of axons inside the microgrooves, the axons entering the microgrooves, and also axons emerging from the channels. Human DAN were introduced to microfluidic devices at day 21 of differentiation and kept for 14 days.

\section{Calcein staining, immunocytochemistry, and microscopy}

To visualize live rat cells by fluorescence, cultures were incubated with $1 \mu \mathrm{M}$ calcein-AM (R\&D Systems) for $15 \mathrm{~min}$. This assay allowed us to clearly identify the growing axons inside the microgrooves of microfluidic devices, which in some cases were difficult to observe in phase-contrast microscopy. For immunodetection, cells in microfluidic devices were fixed with $4 \%$ paraformaldehyde for $20 \mathrm{~min}$ at RT or with methanol for $5 \mathrm{~min}$ at $-20^{\circ} \mathrm{C}$. Cells were permeabilized and blocked for $1 \mathrm{~h}$ at RT with $0.3 \%$ Triton X-100 and $10 \%$ normal goat serum in PBS. Cells were incubated overnight with the following primary antibodies in PBS plus $10 \%$ normal serum: mouse anti- $\beta$ III Tubulin 1:1000 (Covance); rabbit polyclonal anti-TH 1:1000 (Pel-freez). Secondary antibodies were incubated for $2 \mathrm{~h}$ at RT: Alexa-Fluor 488 goat anti-rabbit 1:1000 (Molecular Probes); Alexa 568 goat antimouse 1:1000 (Molecular Probes). For human cells expressing GFP, Alexa 488 was substituted by Alexa Fluor 647 goat anti-rabbit 1:500 (Jackson ImmunoResearch). In all experiments, negative controls that included the addition of only secondary antibodies did not show unspecific staining.

In parallel experiments, the same cell suspensions of human DAN that were used for microfluidic devices were plated on coverslips. After 28 or 35 days of differentiation, immunostaining for NRP1 or NRP2 receptors was made according to published protocols. ${ }^{11}$ In brief, cells were blocked with $10 \%$ horse serum for half an hour, permeabilized with $0.1 \%$ Triton $\mathrm{X}-100$ and 5\% horse serum, and incubated with anti-TH, combined with anti-NRP1 1:500 (R\&D Systems) or anti-NRP2 $\left(1: 2500^{55}\right)$ overnight. Secondary antibodies were incubated for $2 \mathrm{~h}$ at RT (1:1500; Molecular Probes). We calculated the percentage of neurons that coexpress TH/NRP1 (cells counted were 130 for day 28 and 134 for day 35) or TH/NRP2 (total cells assessed were 95 for day 28 and 98 for day 35), in two independent experiments. 


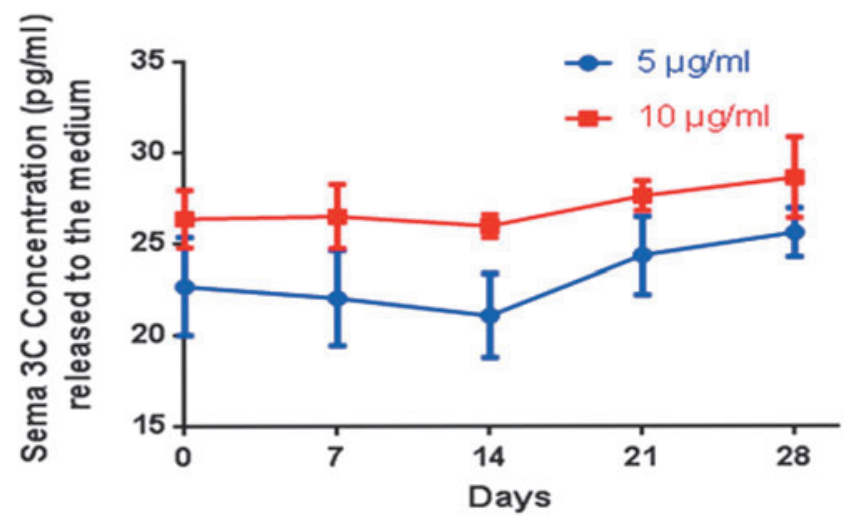

FIG. 1. Release of Semaphorin 3C (Sema3C) embedded in PuraMatrix. Quantification of Sema3C released by the hydrogel at 5 or $10 \mu \mathrm{g} / \mathrm{mL}$ by ELISA. The hydrogel can release Sema3C to the medium at constant levels for 28 days at both tested concentrations. Color images available online at www.liebertpub.com/tea

Explants were processed following reported methods. ${ }^{10}$ Briefly, collagen gels were fixed with $4 \%$ paraformaldehyde for $2 \mathrm{~h}$ at RT. Explants were permeabilized and blocked for $3 \mathrm{~h}$ at RT with $0.3 \%$ Triton X-100 and $10 \%$ normal goat serum in PBS. Collagen gels were exposed to the same primary and secondary antibodies used in microfluidic devices. The times of incubation were extended: explants were exposed to primary antibodies for 2 days and secondary antibodies for 1 day.

Pictures of microfluidic assays with rat cells were taken with a confocal microscope Olympus FV-1000. Microphotographs for experiments with human cells were taken with a confocal microscope Zeiss LSM510. All the capture parameters were the same within groups.

\section{Statistical analysis}

Results are presented as mean \pm standard error of mean for experiments performed in duplicate for at least three independent times. Statistics was made by one-way ANOVA following multiple comparisons test. GraphPad Prism version 6.0 was used for graph and statistical analysis. Statistical differences were considered with a significant $\mathrm{p} \leq 0.05$.

\section{Results}

\section{Hydrogel releases proteins to the medium}

We conjugated recombinant human Sema3C to PuraMatrix hydrogel at two different concentrations $(5$ or $10 \mu \mathrm{g} / \mathrm{mL})$ and measured the release of the protein. We collected the solution in contact with the hydrogel every week and quantified the amount of Sema3C released by ELISA. After 28 days, we detected constant levels of the protein for both concentrations (Fig. 1).

\section{Sema3C released by hydrogel induces attraction of $D A x$}

Collagen gels form a permissive three-dimensional environment for axonal growth ${ }^{50,56-58}$ and also allow the diffusion of molecules. ${ }^{10,16,59}$ To test if hydrogel-released Sema3C could influence the direction of DAx growth, we used a collagen gel culture system that included ventral Mb explants, which contain DAN, together with pretectum (PT) or isthmic region (Ist) explants. We also combined the Mb explants growing in collagen with the polymerized PuraMatrix hydrogel containing either Sema3C or a Cp. We used Mb-PT explants as a positive control because this embryonic region exerts axonal dopaminergic attraction $^{10,60}$; as a negative control, we combined Mb with Ist, which does not attract DAx. ${ }^{10}$ In parallel, we cocultured Mb explants with hydrogel coupled to either $\mathrm{Cp}$ or Sema3C (Fig. 2A). After 5 days, we immunostained for $\mathrm{TH}$ and $\beta$ III Tubulin to visualize the direction of dopaminergic axonal growth. A proximal/distal attraction ratio was calculated as described in Methods (Fig. 2A).

We did not observe growing axons toward Ist in cocultured Mb-Ist explants (Fig. 2B). In contrast, we observed an attractive effect on DAx when $\mathrm{Mb}$ was cocultured with PT (Fig. 2C). We observed a similar attractive effect when $\mathrm{Mb}$ was exposed to the Sema3C-embedded hydrogel, where DAx reached mainly the $\mathrm{P}$ area, and the larger axons grew toward the hydrogel (Fig. 2D). DAx grew in random directions when exposed to hydrogels conjugated to $\mathrm{Cp}$ (Fig. 2E).

Seventy percent of axons in the Mb-PT cocultures showed axonal attraction and $30 \%$ repulsion. In contrast, for the Mb-Ist group, Mb DAx showed repulsion in $65 \%$ of cases, in $12 \%$ attraction, and in $23 \%$ no growth (Fig. $2 \mathrm{~F}$ ). $\mathrm{Mb}$ explants exposed to Sema3C-embedded hydrogel presented $90 \%$ of attraction and $10 \%$ of repulsion, in contrast to DAx exposed to hydrogel with $\mathrm{Cp}$, which showed $64 \%$ of repulsion, $27 \%$ attraction, and $9 \%$ without growth (Fig. 2F).

FIG. 2. Sema3C embedded in PuraMatrix attracts dopaminergic axonal growth. (A) Scheme of collagen gel coculture, including the ventral Mb explant combined with (i) isthmus (Ist); (ii) pretectum (PT); (iii) hydrogel (Hyd) with Sema3C; (iv) Hyd with control protein $(\mathrm{Cp})$. The rat midbrain $(\mathrm{Mb})$ explants were divided into proximal (P) or distal (D) areas as represented. (B) Mb explant cultured with Ist region. Immunostaining with $\beta$ III Tubulin and TH shows that dopaminergic axons (DAx) do not grow toward Ist explant. In all cases, the top pictures are reconstructions of low magnification and the images below are enlargements of the boxed areas. (C) Mb explant cultured with PT. DAx grew toward the PT. (D) Mb explant exposed to Hyd with Sema3C. DAx are preferentially present toward the hydrogel. (E) Mb explant cocultured with Hyd Cp. The axons grow randomly. (F) DAx were classified as proximal, distal, or absence of growth and the proportion of attraction, repulsion, or no growth was calculated. PT and Hyd with Sema3C mainly promote dopaminergic attraction; in contrast, Ist and Hyd with $\mathrm{Cp}$ mostly induced repulsion. (G) P/D ratios were plotted for the different conditions. PT and Hyd Sema3C promoted attraction, whereas Ist and Hyd Cp conditions induced repulsion. No significant differences were found between PT and Hyd Sema3C. (H) The length of DAx regardless of the direction of growth did not change between all the analyzed conditions. Mean \pm standard error of mean $* p<0.05 ; * * p<0.01 ; * * * p<0.001$ (one-way ANOVA and Tukey's multiple comparisons test). Scale bars: $1000 \mu \mathrm{m}$ (reconstruction images) and $100 \mu \mathrm{m}$ (magnification images). Color images available online at www.liebertpub.com/tea 
A

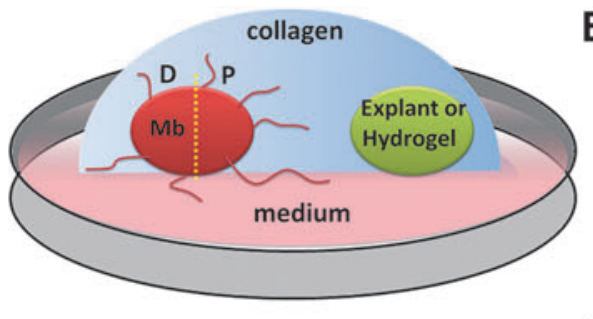

C
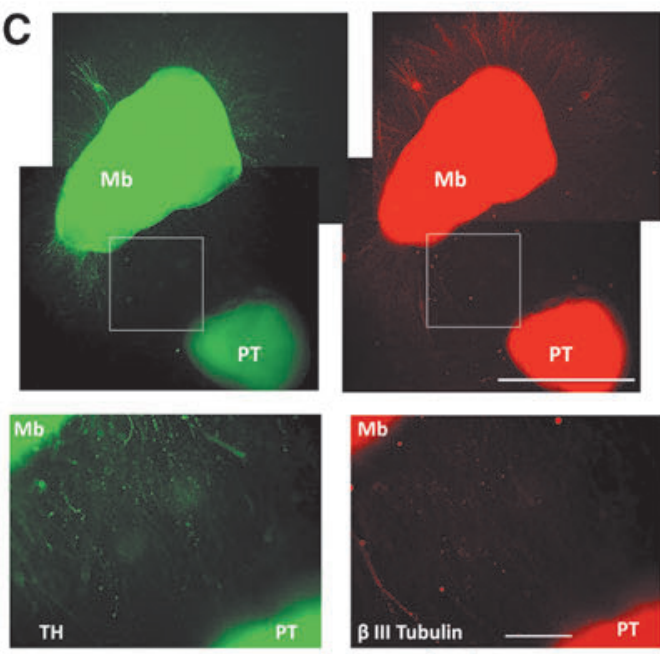

D
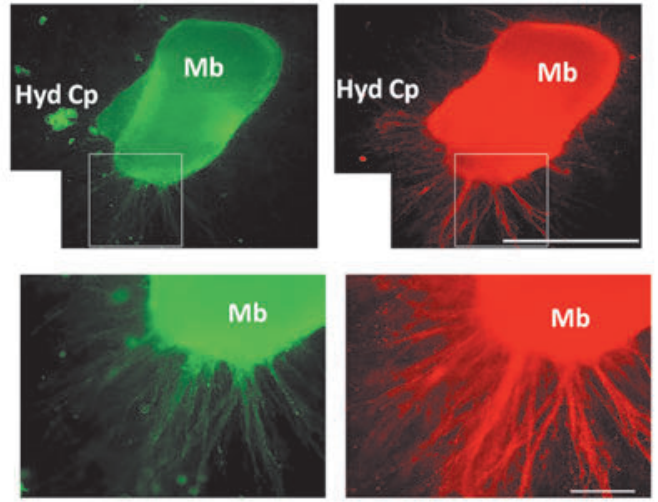

G

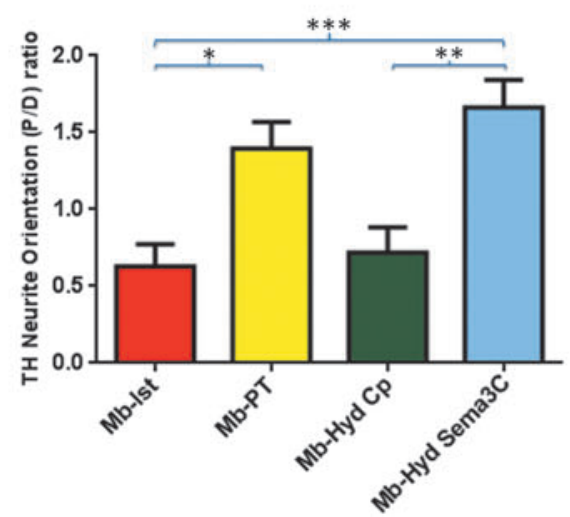

B
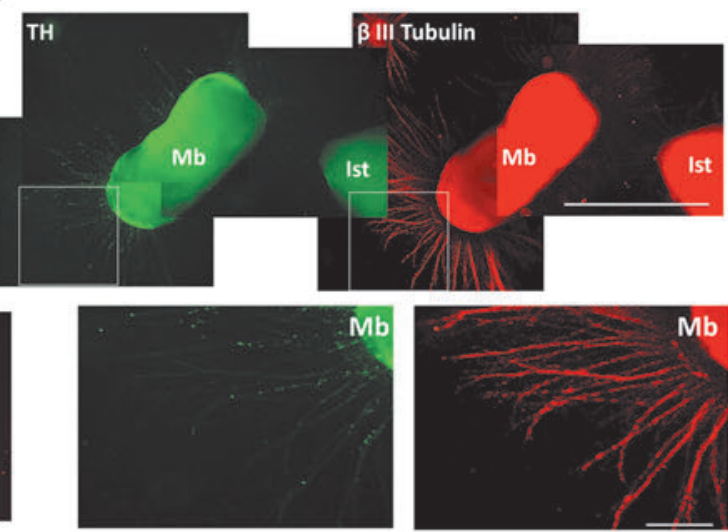

E

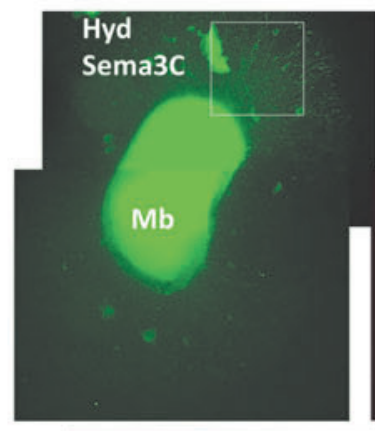

Hyd

Sema3C
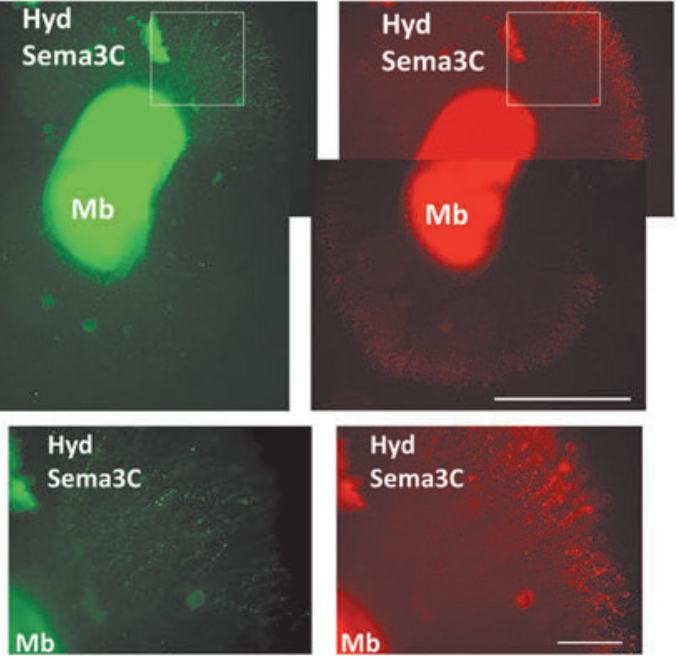

Hyd

Sema3C

$\mathbf{F}$
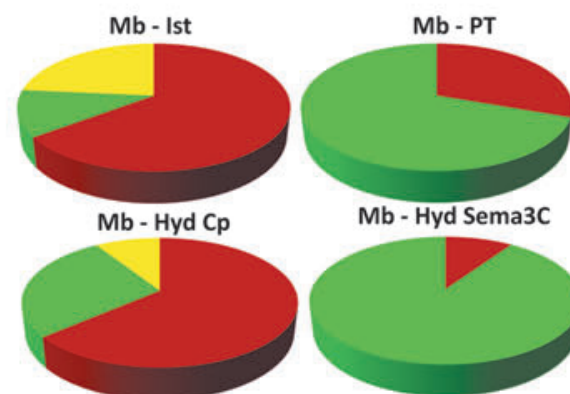

Mb - Hyd Sema3C

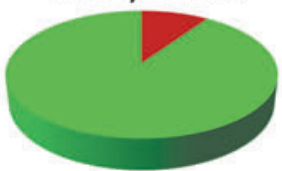

$\square$ Attraction $\square$ Repulsion $\square$ No Growth

H

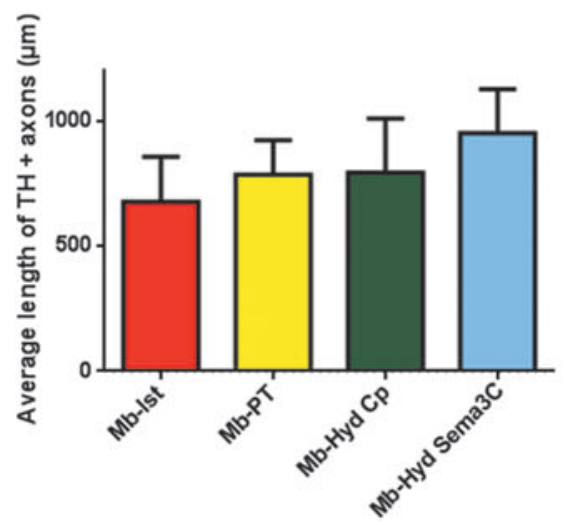


We calculated the proximal/distal ratio to measure dopaminergic attraction in each condition (Fig. 2G). Mb-PT and Mb-hydrogel Sema3C presented proximal/distal ratio values above 1 (Fig. 2G), indicating that Sema3C released by hydrogel attracts DAx similarly to PT. Mb-Ist and Mbhydrogel $\mathrm{Cp}$ cocultures had values below 1 (Fig. 2G). We also measured the length of $\mathrm{TH}+$ axons regardless of their proximal or distal position and found that it was similar in all groups (Fig. 2H).

\section{Sema3C released by hydrogel promotes axonal growth of rat DAN}

To evaluate if Sema3C released by hydrogel could increase DAx length, we used commercial microfluidic devices de- signed to assess the axonal response to soluble molecules. These chambers contain two sides that are separated by microgrooves of $900 \mu \mathrm{m}$ of length (Fig. 3A), since it has been established that only axons are able to grow this distance. ${ }^{61,62}$ One side of the chamber contains more culture medium than the other, creating a hydrostatic force that allows the onedirection movement of soluble molecules from the axonal to the soma compartment (Fig. 3A). As indicated by the scheme, we plated DAN in the soma side of the chamber and Sema3C was present in the axonal compartment. One key advantage of these devices is that axons follow a linear trajectory, in contrast to three-dimensional approaches such as collagen gels. We measured DAx of dissociated rat Mb DAN after 5 days of exposure to different treatments: (1) medium alone; (2) medium plus soluble Sema3C $(20 \mu \mathrm{g} / \mathrm{mL})$; (3) hydrogel
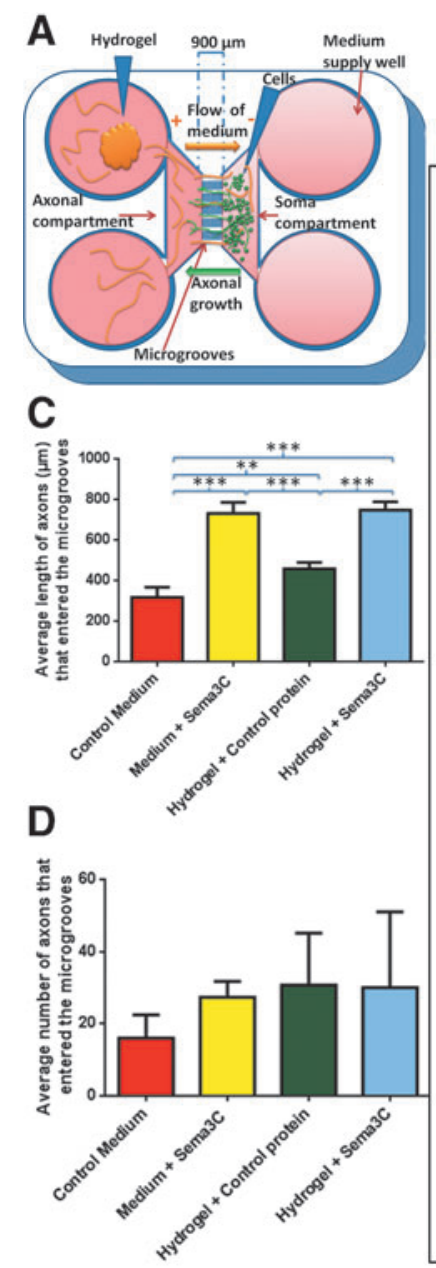
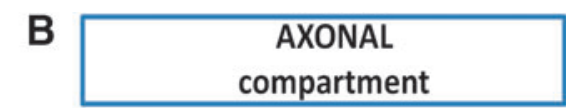

SOMA
compartment
Axons that enter

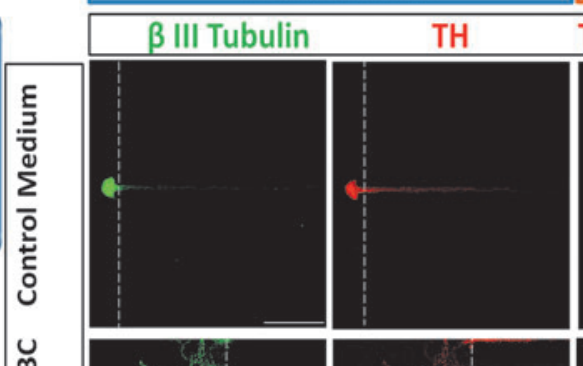

TH / $\beta$ III Tubulin

Calcein
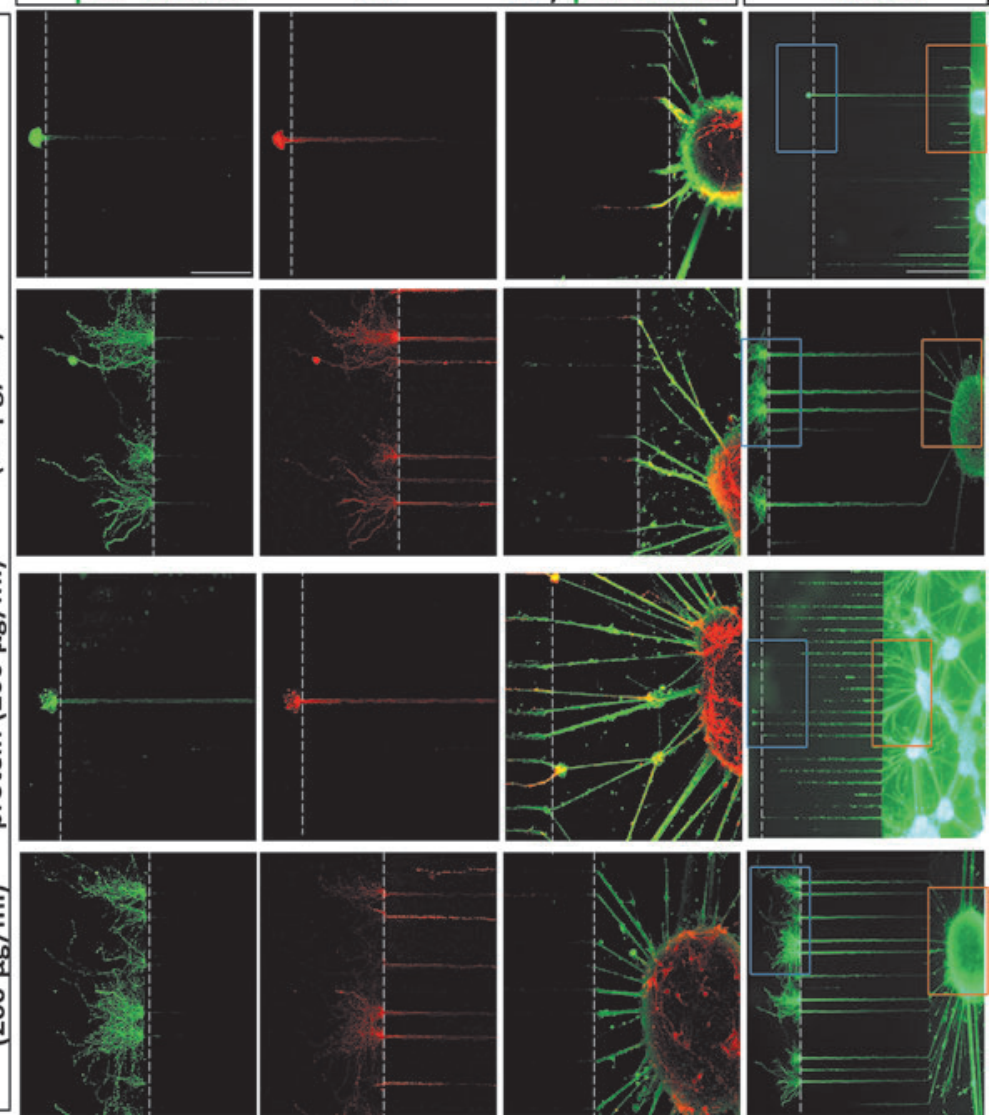

FIG. 3. Axonal growth of embryonic rat dopamine neurons (DAN) is promoted by soluble Sema3C and Sema3C released by hydrogel in microfluidic devices. (A) Scheme of neurons cultured into the microfluidic device. (B) Immunostaining with $\beta$ III Tubulin and TH antibodies shows that in the axonal compartment, there are more and larger DAx in Medium + Sema3C and Hydrogel + Sema3C conditions, compared to control medium and Hydrogel + Cp, respectively. In the soma compartment, the density of $\mathrm{TH} / \beta$ III Tubulin double-positive cells close to the zone of microgrooves is similar in all conditions. In the right panel, a low-magnification picture after live calcein staining is presented. In all cases, axons that entered the microgrooves were similar in number. The orange and blue boxes correspond to the areas in the soma and axonal compartments, respectively. (C) Quantification of total dopaminergic axonal length. Medium + Sema3C and Hydrogel + Sema3C conditions exert a similar effect on axonal growth, in contrast to control medium and Hydrogel $+\mathrm{Cp}$, which had significantly lower levels. (D) In all conditions, the number of DAx that entered to the microgrooves was not statistically different. Mean \pm standard error of mean $* * p<0.01$; $* * * p<0.001$ (one-way ANOVA and Tukey's multiple comparisons test). Scale bars: 100 and $300 \mu \mathrm{m}$ (lowmagnification image of calcein staining). Color images available online at www.liebertpub.com/tea 
coupled to $\mathrm{Cp}(200 \mu \mathrm{g} / \mathrm{mL})$; and (4) hydrogel coupled to Sema3C $(200 \mu \mathrm{g} / \mathrm{mL})$. Calcein staining of live cells revealed that the cell density was similar in all conditions and that neurons group in clusters. A few growing axons of unknown identity can be observed entering and crossing to the axonal compartment (Fig. 3B).

$\beta$ III Tubulin and $\mathrm{TH}$ staining after fixation allowed the identification of DAx. In medium alone, only a few $\mathrm{TH}+$ axons reached the axonal compartment (Fig. 3B). In the case of soluble Sema3C, we observed an increase in the crossing DAx; remarkably, the length and number of branches also increased compared to controls (Fig. 3B). The hydrogel combined with $\mathrm{Cp}$ presented a similar growth as the medium alone. For the Sema3C-hydrogel condition, we found more axons with a higher structural complexity (Fig. 3B). We measured the length of $\mathrm{TH}+$ axons that enter and those that crossed the microgrooves with the ImageJ software. Considering all DAx that enter the microgrooves, soluble Sema3C and Sema3C-hydrogel had significantly longer axons than the corresponding control groups (Fig. 3C). Hydrogel embedded with $\mathrm{Cp}$ increased the length of $\mathrm{TH}+$ processes when compared to control medium. Notwithstanding, the hydrogel + Sema3C condition significantly extended 1.6fold DAx relative to $\mathrm{Cp}$. The average number of DAx that entered the microgrooves was not different between groups (Fig. 3D).

\section{Dopamine neurons differentiated from human ES cells express NRP1 and NRP2 receptors}

We differentiated GFP-expressing H9 human ES cells, according to a published protocol to produce DAN. ${ }^{54}$ Using this protocol, after 28 days, $36.6 \%$ of neurons were $\mathrm{TH}+$, and this proportion increased to $46.6 \%$ at day 35 of differentiation. To determine if DAN obtained from human ES cells express NRP1 or NRP2, receptors required to respond to Sema3C, we immunostained cells derived from the same cell suspension used for the assays with microfluidic devices presented below. At day 28, we quantified $\mathrm{TH}+$ neurons and observed that NRP1 was present in $86 \%$ of DAN and $87.6 \%$ of cells were double-positive for NRP2 and TH. This high proportion was preserved in differentiated cultures of 35 days (Fig. 4), where we observed $88.8 \%$ and $90 \%$ of colocalization of TH with NRP1 or NRP2, respectively.

\section{Sema3C released by hydrogel promotes dopaminergic axonal growth in neurons differentiated from human ES cells}

At 21 days of differentiation, human ES cells were dissociated and plated on microfluidic devices. Immunostaining for $\beta$ III Tubulin and $\mathrm{TH}$ showed that treatments with soluble Sema3C or Sema3C-hydrogel promoted the growth of more and larger DAx, in sharp contrast to treatments with medium only and hydrogel-Cp (Fig. 5A). In the soma compartment, the density of $\mathrm{TH} / \beta$ III Tubulin doublepositive neurons was similar in all conditions. The right column of Fig. 5A shows a low-magnification GFP image, where it can be appreciated that the proportion of axons that entered the microgrooves is similar in all conditions. The orange and blue boxes correspond to the areas in the soma and axonal compartments, respectively. Similar to the ob-
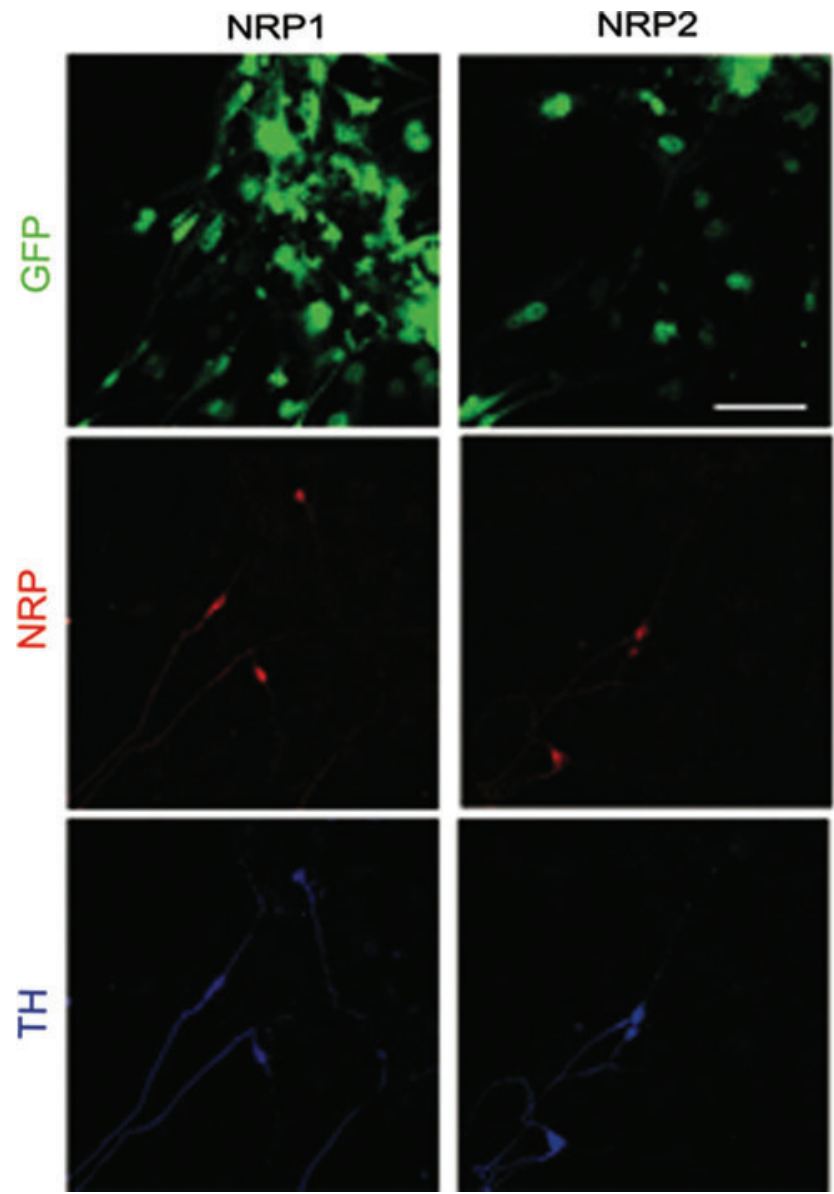

FIG. 4. Dopaminergic neurons differentiated from human embryonic stem (ES) cells express NRP1 and NRP2 in a high proportion. Immunostaining with specific antibodies for TH and either NRP1 or NRP2 shows that DAN from day 35 of differentiation presented a high proportion of cells positive for NRP1 and NRP2. GFP is also shown to observe cell density. Scale bar: $100 \mu \mathrm{m}$. Color images available online at www.liebertpub.com/tea

servations in the rat mesencephalic neurons, the average length of axons was significantly higher in soluble Sema3C and Sema3C-hydrogel than in their corresponding controls (Fig. 5B). The axons located in the microgrooves were similar in all studied conditions (Fig. 5C).

\section{Discussion}

In this study, we show that hydrogel-embedded Sema3C is released to the medium maintaining constant levels of the protein for at least 28 days. PuraMatrix was reported to incorporate and release different molecules such as basic fibroblast growth factor, vascular endothelial growth factor, BDNF, bovine serum albumin, immunoglobulin $\mathrm{G}$, and insulin. ${ }^{48,63,64}$ Our results confirm that proteins released by this hydrogel are functional as they exert the expected function in vitro. ${ }^{48,63}$ All these proteins have molecular weights between 7 and $38 \mathrm{kDa}$; Sema3C has a higher mass $(82 \mathrm{kDa})$, but still can be released by PuraMatrix.

Using a three-dimensional collagen assay, we demonstrated in vitro that DAx of neurons differentiated from 

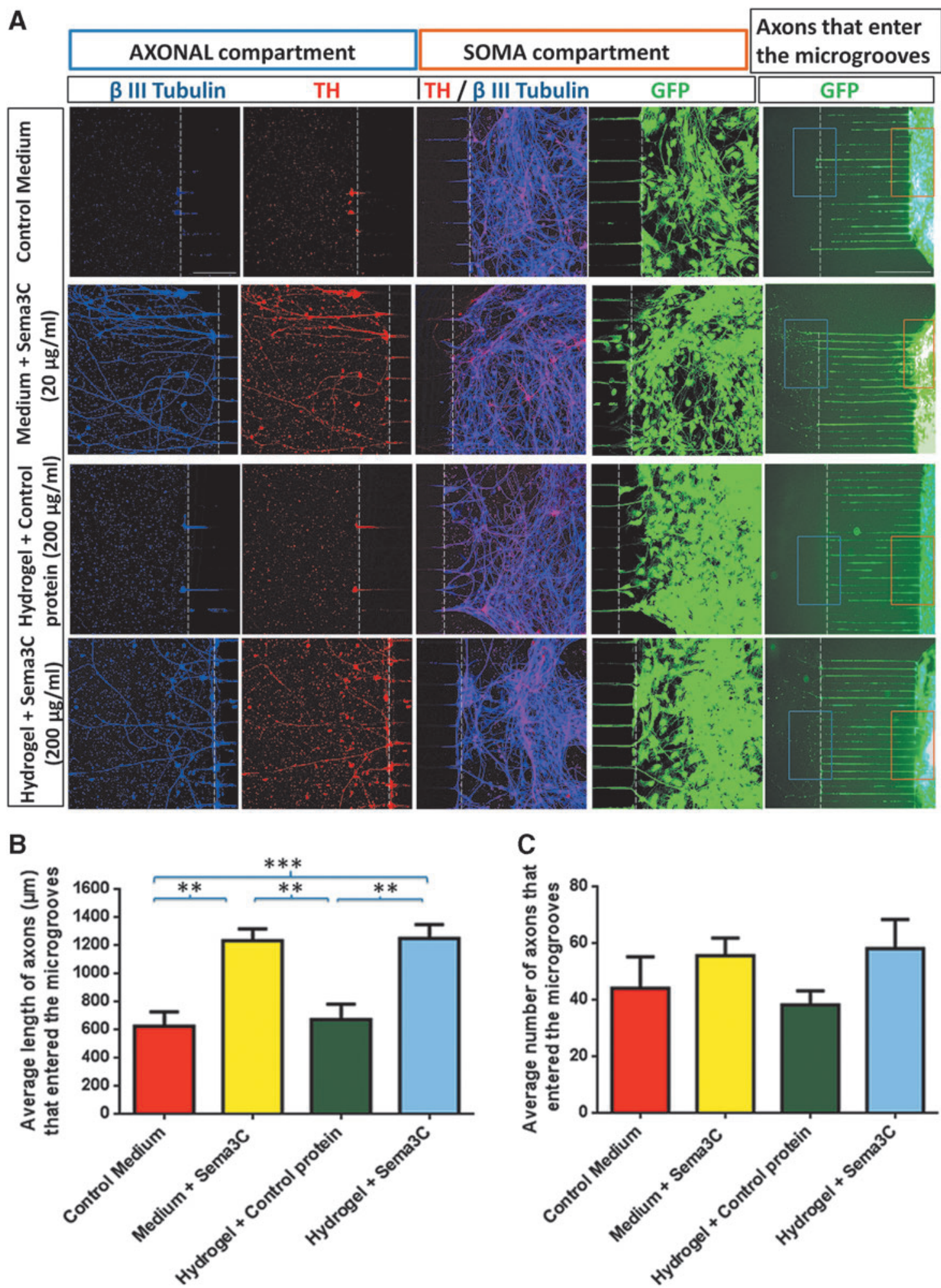

FIG. 5. The axonal growth of human ES cells differentiated to DAN is promoted by Sema3C. Dopamine cells were studied in microfluidic devices in control (medium alone or hydrogel-Cp) or Sema3C (either soluble or coupled to hydrogel) conditions. (A) Immunostaining for $\beta$ III Tubulin and TH shows that in the axonal compartment, there are more DAx in Medium + Sema3C and in Hydrogel + Sema3C conditions, compared to control medium and Hydrogel $+\mathrm{Cp}$, respectively. In the soma compartment, a similar density of neurons positive for both TH and $\beta$ III Tubulin is found close to the zone of microgrooves. The H9 ES cells express GFP that was used to visualize cell density in the soma compartment. In the right-most panel, a low magnification picture of the GFP+ axons in the microgrooves is shown. Note that in Medium + Sema3C and Hydrogel + Sema3C conditions, many axons were larger than the microgroove length $(900 \mu m)$. (B) Quantification of total dopaminergic axonal length. Medium + Sema3C and Hydrogel + Sema3C conditions exert a positive effect in length, in contrast to control medium and Hydrogel $+\mathrm{Cp}$, which had significantly shorter axons. (C) In all conditions, a similar number of DAx entered the microgrooves. Mean \pm standard error of mean $* * p<0.01 ; * * * p<0.001$ (one-way ANOVA following Tukey's multiple comparisons test). Scale bars: 100 and $300 \mu \mathrm{m}$. Color images available online at www.liebertpub.com/tea 
mouse ES cells are attracted by Sema3C released by aggregated HEK cells. ${ }^{10}$ The current study shows that the PT embryonic region exerts axonal attraction, in contrast to the Ist region, which does not. Exposure of $\mathrm{Mb}$ explants to hydrogels coupled to Sema3C generates a similar attractive effect to that observed in PT. Conversely, hydrogel with $\mathrm{Cp}$ has analogous effects to that of Ist explants. These results indicate that the use of hydrogel coupled to Sema3C guides DAx growth, with a comparable efficiency to PT, which attracts these axons during development. Using a similar methodological approach, other groups have demonstrated that Netrin-1 exerts dopaminergic axonal attraction. ${ }^{12,14,16}$ To our knowledge, the current report is the first in which an hydrogel alone is able to deliver a molecule that guides dopaminergic axonal growth. Some articles showed that hydrogels can be used as scaffolds that require the combination with other particles that release molecules in vitro: a scaffold of synthetic poly(ethylene glycol) gel conjugated with biodegradable poly-lactic-co-glycolic acid particles with different concentrations of insulin-like growth factor directed the axonal growth of mouse ES cell-derived neurons. ${ }^{65}$ An increase of the axonal length of peripheral nervous system neurons with a scaffold of agarose hydrogel, combined with collagen and poly-lactic-co-glycolic acid particles that released nerve growth factor (NGF), has been also demonstrated. ${ }^{66}$ On the contrary, the guidance of axons during development is influenced by several molecules that interplay, sometimes with opposite effects, to direct axonal growth. The use of a choice point system allows the assessment of various cues simultaneously. A device based on immobilized and soluble proteins with different gradients was recently developed to test the effects of Sema6A and NGF on the axonal growth of dorsal root ganglia. ${ }^{67}$ Sema6A induces repulsion of neurite growth of sensory neurons of the lumbosacral region, but not other spinal regions, and NGF can attenuate this effect.

Collagen gels have been used previously to evaluate axonal growth. ${ }^{11}$ In such a matrix, axons can develop in all directions, making difficult to follow a trajectory in one plane. Thus, the measurement even with specialized software can be challenging. Therefore, we decided to use microfluidic devices, in which axons follow a linear trajectory for $900 \mu \mathrm{m}$ in one plane. This system has been used to evaluate the effect of diffusible molecules on growing axons. ${ }^{61,62}$ In this work, we specifically looked at the effects of Sema3C using these devices, which unequivocally identify growing axons. Using DAN of rodent and human origin, we found that exposure of such neurons to hydrogel embedded with Sema3C results in an increase of DAx length, similar to soluble Sema3C. Therefore, Sema3C released by PuraMatrix seems to be equally functional as the soluble form, with regard to promotion of DAx growth, although with a 10-fold higher initial concentration. It is noteworthy that the times required to observe axonal growth in rodent and human neurons were different. PuraMatrix-released Sema3C was effective for rat cells (5 days) and also for human neurons (15 days), strongly suggesting that the delivery time of Sema3C by the hydrogel was optimal for these assays.

Microfluidic devices have been used to isolate axons of neurons differentiated from human ES cells, to observe mitochondrial movement across axons, ${ }^{68}$ to evaluate axonal injury, regeneration, and transport, ${ }^{62}$ to assess differentiation and neuronal entrance to microgrooves, ${ }^{69}$ and to identify bidirectional communication between motor neurons and muscle cells. ${ }^{70}$ Microfluidic systems with different characteristics in design have also been successfully used for generating chemical gradients and evaluating axonal growth cone responses. ${ }^{71}$ Previous data from our group have indicated that Sema3C increases DAx growth in vitro ${ }^{11}$ of DAN obtained from mouse ES. This is the first report on the positive effects of Sema3C on DAN derived from human ES cells, suggesting similar responses between human and rodent cells. We show that the dopaminergic differentiation protocol for human cells $^{54}$ used in this study, as well as the protocol for rodent cells used previously, ${ }^{21}$ generates DAN neurons that respond to Sema3C. In fact, this response of human DAN was correlated with a high proportion of $\mathrm{TH}+$ neurons that express the Sema3C receptors NRP1 and NRP2.

Previously, the presence of NRP1 and NRP2 has been demonstrated in DAN obtained from the developing rat ventral $\mathrm{Mb}$ and DAN differentiated from mouse ES. These rodent DAN presented similar high proportions of $\mathrm{TH}+$ neurons that express NRP1 (77\% for rat and $82 \%$ for mouse) or NRP2 (48 for rat and $59 \%$ for mouse). Blocking antibodies for these receptors inhibit the action of Sema3C on attraction and axonal extension. ${ }^{11}$ Therefore, it was of interest to analyze if human DAN express NRP1 and NRP2 since no previous reports were available. Our results show that approximately $90 \%$ of DAN derived from human ES presented immunoreactivity to anti-NRP1 or anti-NRP2 antibodies, suggesting that the effects of Sema3C to promote axonal growth are mediated by these receptors.

Grafting DAN into the striatum of parkinsonian rats provides recovery in apomorphine- or amphetamine-induced rotational test. ${ }^{20-25}$ However, this ectopic graft induces behavioral complications such as increasing levodopa-induced dyskinesias. ${ }^{72,73}$ Furthermore, grafts in the putamen do not cause a consistent and steady recovery in PD patients. ${ }^{26,27}$ An alternative to such ectopic grafts in experimental animals is placing DAN in the SN and guiding DAx to reach the dorsal striatum. Previous data from our group have demonstrated that the intranigral graft of DAN derived from mouse ES cells, combined with HEK cells transfected with Sema3C, along an artificial trajectory from $\mathrm{SN}$ to striatum, promotes behavioral recovery of parkinsonian rats lesioned with 6OHDA after 3 weeks. ${ }^{25}$ We report that Sema3C release was maintained during 4 weeks in vitro, so we can speculate that the use of this biomaterial scaffold could replace HEK cells to promote and guide axonal growth in vivo.

We used a biocompatible and biodegradable hydrogel that has been implanted into rodent brain ${ }^{36,43,47}$ with negligible glial reaction. This is a key issue, because hydrogels should incorporate and release proteins but without adverse tissue reactions. For example, a Poly-(ethylene glycol)-silica hydrogel has been used to release Sema3A, which in vitro promotes DAx growth; however, when it was implanted into the rat brain, the hydrogel produced an inflammatory response. ${ }^{74}$ Our results suggest that it might be possible to use PuraMatrix combined with Sema3C to promote and guide axonal growth in animal models of PD, using of DAN differentiated from human ES cells.

In addition to the effect of Sema3C on axonal growth, this protein can influence the development of new vessels, which has implications on vision. Sema3C inhibits the formation 
of pathological endothelial tufts in an animal model of retinopathy of prematurity. This protein, acting through NRP1 and Plexin D1, prevented AKT- and P38 MAPK-induced phosphorylations, resulting in apoptosis of developing microvasculature, decreased branching, loss of sprouting tips, and abnormal cell junctions. ${ }^{75}$ It might be of interest to test if the controlled release of Sema3C by a hydrogel could be applied in this model.

\section{Conclusion}

In this study, we demonstrate that Sema3C can be embedded in the PuraMatrix hydrogel and this protein is released for at least 28 days in vitro. Hydrogel-released Sema3C can attract the growth of rodent embryonic DAx in a similar way to that of PT in collagen gels and also increases the axonal growth of human and rodent DAN. Remarkably, the response of these human neurons to Sema3C is very similar to that of rodent cells. This is the first time that a hydrogel is used as a protein carrier to increase dopaminergic axonal length.

\section{Acknowledgments}

The work in the laboratory of I.V. is supported by grants from Conacyt (131281 and Red Temática Células Troncales y Medicina Regenerativa) and Papiit-UNAM (IN208713 and IN213716). O.A.C.-M. is a doctoral student from Programa de Doctorado en Ciencias Biomédicas, Universidad Nacional Autónoma de México (UNAM), and received fellowship 256229 from Conacyt. This study was performed in partial fulfillment of the requirements for the $\mathrm{PhD}$ degree in Biomedical Sciences of O.A.C.-M., V.R.-M. is supported by the FIS/ISCIII-FEDER CP12/03175 and PI14/01412. The support of Dr. J. Adolfo García-Sáinz to obtain human ES cells is highly appreciated. We thank Dr. Alfredo Varela Echavarría for technical support in collagen extraction and donation of antibodies for Neuropilin1 and Neuropilin2. We also thank the technical support of Dr. Daniel Cortés, Dr. Humberto Gutiérrez and Dr. Fabián Díaz.

\section{Disclosure Statement}

No competing financial interests exist.

\section{References}

1. Liu, B.P., and Strittmatter, S.M. Semaphorin-mediated axonal guidance via Rho-related G proteins. Curr Opin Cell Biol 13, 619, 2001.

2. Goldberg, J.L. How does an axon grow? Genes Dev 17, 941, 2003.

3. Chisholm, A., and Tessier-Lavigne, M. Conservation and divergence of axon guidance mechanisms. Curr Opin Neurobiol 9, 603, 1999.

4. Luo. Y., Raible, D., and Raper, J.A. Collapsin: a protein in brain that induces the collapse and paralysis of neuronal growth cones. Cell 75, 217, 1993.

5. Castellani, V., Chédotal, A., Schachner, M., Faivre-Sarrailh, C., and Rougon, G. Analysis of the L1-deficient mouse phenotype reveals cross-talk between Sema3A and L1 signaling pathways in axonal guidance. Neuron 27, 237, 2000.
6. Steinbach, K., Volkmer, H., and Schlosshauer, B. Semaphorin 3E/Collapsin-5 inhibits growing retinal axons. Exp Cell Res 279, 52, 2002.

7. Niquille, M., Garel, S., Mann, F., Hornung, J., Otsmane, B., Parras, C., et al. Transient neuronal populations are required to guide callosal axons: a role for semaphorin $3 \mathrm{C}$. PLoS Biol 7, 1, 2009.

8. Bellon, A., Luchino, J., Haigh, K., Rougon, G., Haigh, J., Sophie, C., et al. VEGFR2 (KDR/Flk1) signaling mediates axon growth in response to semaphorin $3 \mathrm{E}$ in the developing brain. Neuron 2, 205, 2010.

9. Torre, E.R., Gutekunst, C.A., and Gross, R.E. Expression by midbrain dopamine neurons of Sema3A and $3 \mathrm{~F}$ receptors is associated with chemorepulsion in vitro but a mild in vivo phenotype. Mol Cell Neurosci 44, 135, 2010.

10. Hernández-Montiel, H.L., Tamariz, E., Sandoval-Minero, M.T., and Varela-Echavarría, A. Semaphorins 3A, 3C, and 3F in mesencephalic dopaminergic axon. J Comp Neurol 506, 387, 2008.

11. Tamariz, E., Díaz-Martínez, N.E., Díaz, N.F., García-Peña, C.M., Velasco, I., and Varela-Echavarría A. Axon responses of embryonic stem cell-derived dopaminergic neurons to semaphorins 3A and 3C. J Neurosci Res 88, 971, 2010.

12. Lin, L., Rao, Y., and Isacson, O. Netrin-1 and slit-2 regulate and direct neurite growth of ventral midbrain dopaminergic neurons. Mol Cell Neurosci 28, 547, 2005.

13. Dugan, J.P., Stratton, A., Riley, H.P., Farmer, W.T., and Mastick, G.S. Midbrain dopaminergic axons are guided longitudinally through the diencephalon by Slit/Robo signals. Mol Cell Neurosci 46, 347, 2011.

14. Kim, M., Farmer, W.T., Bjorke, B., McMahon, S.A., Fabre, P.J., Charron, F., et al. Pioneer midbrain longitudinal axons navigate using a balance of Netrin attraction and Slit repulsion. Neural Dev 9, 1, 2014.

15. Kastenhuber, E., Kern, U., Bonkowsky, J.L., Chien, C-B., Driever, W., and Schweitzer. J. Netrin-DCC, Robo-Slit, and heparan sulfate proteoglycans coordinate lateral positioning of longitudinal dopaminergic diencephalospinal axons. J Neurosci 29, 8914, 2009.

16. Li, J., Duarte, T., Kocabas, A., Works, M., McConnell, S.K., and Hynes, M.A. Evidence for topographic guidance of dopaminergic axons by differential Netrin-1 expression in the striatum. Mol Cell Neurosci 61, 85, 2014.

17. Gurgo, R.D., Bedi, K.S., and Nurcombe, V. Current concepts in central nervous system regeneration. J Clin Neurosci 9, 613, 2002.

18. Yiu, G., and He, Z. Glial inhibition of CNS axon regeneration. Nat Rev Neurosci 7, 617, 2006.

19. Fitch, M.T., and Silver, J. CNS injury, glial scars, and inflammation: inhibitory extracellular matrices and regeneration failure. Exp Neurol 209, 294, 2008.

20. Rodríguez-Gómez, J.A., Lu, J-Q., Velasco, I., Rivera, S., Zoghbi, S.S., Liow, J-S., et al. Persistent dopamine functions of neurons derived from embryonic stem cells in a rodent model of Parkinson disease. Stem Cells 25, 918, 2007.

21. Kim, J-H., Auerbach, J.M., Rodríguez-Gómez, J.A., Velasco, I., Gavin, D., Lumelsky, N., et al. Dopamine neurons derived from embryonic stem cells function in an animal model of Parkinson's disease. Nature 418, 50, 2002.

22. Baier, P.C., Schindehütte, J., Thinyane, K., Flügge, G., Fuchs, E., Mansouri, A., et al. Behavioral changes in unilaterally 6-hydroxy-dopamine lesioned rats after transplantation 
of differentiated mouse embryonic stem cells without morphological integration. Stem Cells 22, 396, 2004.

23. Yurek, D.M., and Fletcher-Turner, A. Comparison of embryonic stem cell-derived dopamine neuron grafts and fetal ventral mesencephalic tissue grafts: morphology and function. Cell Transpl 13, 295, 2004.

24. Grealish, S., Diguet, E., Kirkeby, A., Mattsson, B., Heuer, A., Bramoulle, Y., et al. Human ESC-derived dopamine neurons show similar preclinical efficacy and potency to fetal neurons when grafted in a rat model of Parkinson's disease. Cell Stem Cell 15, 653, 2014.

25. Díaz-Martínez, N.E., Tamariz, E., Díaz, N.F., García-Peña, C.M., Varela-Echavarría, A., and Velasco, I. Recovery from experimental parkinsonism by semaphorin-guided axonal growth of grafted dopamine neurons. Mol Ther 21, 1579, 2013.

26. Olanow, C.W., Goetz, C.G., Kordower, J.H., Stoessl, A.J., Sossi, V., Brin, M.F., et al. A double-blind controlled trial of bilateral fetal nigral transplantation in Parkinson's disease. Ann Neurol 54, 403, 2003.

27. Freed, C.R., Greene, P.E., Breeze, R.E., Tsai, W-Y., DuMouchel, W., Kao, R., et al. Transplantation of embryonic dopamine neurons for severe Parkinson's disease. N Engl J Med 344, 710, 2001.

28. Mendez, I., Sadi, D., and Hong, M. Reconstruction of the nigrostriatal pathway by simultaneous intrastriatal and intranigral dopaminergic transplants. J Neurosci 16, 7216, 1996.

29. Mukhida, K., Baker, K.A., Sadi, D., and Mendez, I. Enhancement of sensorimotor behavioral recovery in hemiparkinsonian rats with intrastriatal, intranigral, and intrasubthalamic nucleus dopaminergic transplants. J Neurosci 21, 3521, 2001.

30. Olsson, M., Nikkhah, G., Bentlage, C., and Björklund, A. Forelimb akinesia in the rat Parkinson model: differential effects of dopamine agonists and nigral transplants as assessed by a new stepping test. J Neurosci 15, 3863, 1995.

31. Aurand, E.R., Lampe, K.J., and Bjugstad, K.B. Defining and designing polymers and hydrogels for neural tissue engineering. Neurosci Res 72, 199, 2012.

32. Hoffman, A.S. Hydrogels for biomedical applications. Adv Drug Deliv Rev 64, 18, 2012.

33. Jeong, B., Bae, Y.H., and Kim, S.W. In situ gelation of PEG-PLGA-PEG triblock copolymer aqueous solutions and degradation thereof. J Biomed Mater Res 50, 171, 2000.

34. He, S., Yaszemski, M.J., Yasko, A.W., Engel, P.S, and Mikos, A.G. Injectable biodegradable polymer composites based on poly(propylene fumarate) crosslinked with poly(ethylene glycol)-dimethacrylate. Biomaterials 21, 2389, 2000.

35. Nagai, Y., Unsworth, L.D., Koutsopoulos, S., and Zhang, S. Slow release of molecules in self-assembling peptide nanofiber scaffold. J Control Release 115, 18, 2006.

36. Ellis-Behnke, R.G., Liang, Y-X., You, S-W., Tay, D.K.C., Zhang, S., So, K-F., et al. Nano neuro knitting: peptide nanofiber scaffold for brain repair and axon regeneration with functional return of vision. Proc Natl Acad Sci U S A 103, 5054, 2006.

37. Carballo-Molina, O.A., and Velasco, I. Hydrogels as scaffolds and delivery systems to enhance axonal regeneration after injuries. Front Cell Neurosci 9, 13, 2015.

38. Fon, D., Al-Abboodi, A., Chan, P.P.Y., Zhou, K., Crack, P., Finkelstein, D.I., et al. Effects of GDNF-loaded injectable gelatin-based hydrogels on endogenous neural progenitor cell migration. Adv Healthc Mater 3, 761, 2014.

39. Jain, A., Kim, Y-T., McKeon, R.J., and Bellamkonda, R. V. In situ gelling hydrogels for conformal repair of spinal cord defects, and local delivery of BDNF after spinal cord injury. Biomaterials 27, 497, 2006.

40. Burdick, J.A., Ward, M., Liang, E., Young, M.J., and Langer, R. Stimulation of neurite outgrowth by neurotrophins delivered from degradable hydrogels. Biomaterials 27, 452, 2006.

41. Banerjee, A., Arha, M., Choudhary, S., Ashton, R.S., Bhatia, S.R., Schaffer, D. V., et al. The influence of hydrogel modulus on the proliferation and differentiation of encapsulated neural stem cells. Biomaterials 30, 4695, 2009.

42. Egawa, E.Y., Kato, K., Hiraoka, M., Nakaji-Hirabayashi, T., and Iwata, H. Enhanced proliferation of neural stem cells in a collagen hydrogel incorporating engineered epidermal growth factor. Biomaterials 32, 4737, 2011.

43. Cheng, T., Chen, M., Chang, W., Huang, M., and Wang, T. Neural stem cells encapsulated in a functionalized selfassembling peptide hydrogel for brain tissue engineering. Biomaterials 34, 2005, 2013.

44. Novikova, L.N., Mosahebi, A., Wiberg, M., Terenghi, G., Kellerth, J., and Novikov, L.N. Alginate hydrogel and matrigel as potential cell carriers for neurotransplantation. $\mathbf{J}$ Biomed Mater Res A 77, 242, 2006.

45. Ortinau, S., Schmich, J., Block, S., Liedmann, A., Jonas, L., Weiss, D.G., et al. Effect of 3D-scaffold formation on differentiation and survival in human neural progenitor cells. Biomed Eng Online 9, 70, 2010.

46. Holmes, T.C., de Lacalle, S., Su, X., Liu, G., Rich, A., and Zhang, S. Extensive neurite outgrowth and active synapse formation on self-assembling peptide scaffolds. Proc Natl Acad Sci U S A 97, 6728, 2000.

47. Guo, J., Leung, K.K., Su, H., Yuan, Q., Wang, L., Chu, TH., et al. Self-assembling peptide nanofiber scaffold promotes the reconstruction of acutely injured brain. Nanomedicine 5, 345, 2009.

48. Gelain, F., Unsworth, L.D., and Zhang, S. Slow and sustained release of active cytokines from self-assembling peptide scaffolds. J Control Release 145, 231, 2010.

49. Yokoi, H., Kinoshita, T., and Zhang, S. Dynamic reassembly of peptide RADA16 nanofiber scaffold. Proc Natl Acad Sci U S A 102, 8414, 2005.

50. Guthrie, S., and Lumsden, A. Collagen gel coculture of neural tissue. Neuroprotocols 4, 116, 1994.

51. Meijering, E., Jacob, M., Sarria, J-C.F., Steiner, P., Hirling, H., and Unser, M. Design and validation of a tool for neurite tracing and analysis in fluorescence microscopy images. Cytometry A 58A, 167, 2004.

52. Schmidt, E.R.E., Morello, F., and Pasterkamp, R.J. Dissection and culture of mouse dopaminergic and striatal explants in three-dimensional collagen matrix assays. J Vis Exp 61, e3691, 2012.

53. Ramos-Mejía, V., Navarro-Montero, O., Bueno, C., Romero, T., Real, P.J., and Menendez, P. HOXA9 promotes hematopoietic commitment of human embryonic stem cells. Blood 124, 3065, 2014.

54. Kriks, S., Shim, J-W., Piao, J., Ganat, Y.M., Wakeman, D.R., Xie, Z., et al. Dopamine neurons derived from human ES cells efficiently engraft in animal models of Parkinson's disease. Nature 480, 547, 2011.

55. Kolodkin, A.L., Levengood, D.V., Rowe, E.G., Tai, Y., Giger, R.J., and Ginty, D.D. Neuropilin is a Semaphorin III receptor. Cell 90, 753, 1997.

56. Koutsopoulos, S., and Zhang, S. Long-term three-dimensional neural tissue cultures in functionalized self-assembling peptide 
hydrogels, matrigel and collagen I. Acta Biomater 9, 5162, 2013.

57. Yoshii, S., Oka, M., Shima, M., Taniguchi, A., Taki, Y., and Akagi, M. Restoration of function after spinal cord transection using a collagen bridge. J Biomed Mater Res A 70, 569, 2004.

58. Xu, T., Molnar, P., Gregory, C., Das, M., Boland, T., and Hickman, J.J. Electrophysiological characterization of embryonic hippocampal neurons cultured in a 3D collagen hydrogel. Biomaterials 30, 4377, 2009.

59. Gil, V., del Río, J.A. Analysis of axonal growth and cell migration in 3D hydrogel cultures of embryonic mouse CNS tissue. Nat Protoc 7, 268, 2012.

60. Wakita, S., Izumi, Y., Matsuo, T., Kume, T., Takada-Takatori, Y., Sawada, H, et al. Reconstruction and quantitative evaluation of dopaminergic innervation of striatal neurons in dissociated primary cultures. J Neurosci Methods 192, 83, 2010.

61. Kim, H.J., Park, J.W., Park, J.W, Byun, J.H., Vahidi, B., Rhee, S.W., et al. Integrated microfluidics platforms for investigating injury and regeneration of CNS axons. Ann Biomed Eng 40, 1268, 2012.

62. Taylor, A.M., Blurton-Jones, M., Rhee, S.W., Cribbs, D.H., Cotman, C.W., and Jeon, N.L. A microfluidic culture platform for CNS axonal injury, regeneration and transport. Nat Methods 2, 599, 2005.

63. Nishimura, A., Hayakawa, T., Yamamoto, Y., Hamori, M., Tabata, K., Seto, K., et al. Controlled release of insulin from self-assembling nanofiber hydrogel, PuraMatrix ${ }^{\mathrm{TM}}$ : application for the subcutaneous injection in rats. Eur $\mathbf{J}$ Pharm Sci 45, 1, 2012.

64. Koutsopoulos, S., Unsworth, L.D., Nagai, Y., and Zhang, S. Controlled release of functional proteins through designer self-assembling peptide nanofiber hydrogel scaffold. Proc Natl Acad Sci U S A 106, 4623, 2009.

65. Lee, W., Frank, C.W., and Park, J. Directed axonal outgrowth using a propagating gradient of IGF-1. Adv Mater 26, 4936, 2014.

66. Alsmadi, N.Z., Patil, L.S., Hor, E.M., Lofti, P., Razal, J.M., Chuong. C-J., et al. Coiled polymeric growth factor gradients for multi-luminal neural chemotaxis. Brain Res 1619, 72, 2015.

67. Curley, J.L., Catig, G.C., Horn-Ranney, E.L., and Moore, M.J. Sensory axon guidance with semaphorin 6A and nerve growth factor in a biomimetic choice point model. Biofabrication 6, 035026, 2014.

68. Shin, H.S., Kim, H.J., Min, S.K., Kim, S.H., Lee, B.M., and Jeon, N.L. Compartmental culture of embryonic stem cell- derived neurons in microfluidic devices for use in axonal biology. Biotechnol Lett 32, 1063, 2010.

69. Lee, N., Park, J.W., Kim, H.J., Yeon, J.H., Kwon, J., Ko, J.J., et al. Monitoring the differentiation and migration patterns of neural cells derived from human embryonic stem cells using a microfluidic culture system. Mol Cells. 37, 497, 2014.

70. Zahavi, E.E., Ionescu, A., Gluska, S., Gradus, T., BenYaakov, K., and Perlson, E. A compartmentalized microfluidic neuromuscular co-culture system reveals spatial aspects of GDNF functions. J Cell Sci 128, 1241, 2015.

71. Wang, J.C., Li, X., Lin, B., Shim, S., Ming, G-L., and Levchenko, A. A microfluidics-based turning assay reveals complex growth cone responses to integrated gradients of substrate-bound ECM molecules and diffusible guidance cues. Lab Chip 8, 227, 2008.

72. Steece-Collier, K., Collier, T.J., Danielson, P.D., Kurlan, R., Yurek, D.M., and Sladek, J.R. Embryonic mesencephalic grafts increase levodopa-induced forelimb hyperkinesia in parkinsonian rats. Mov Disord 18, 1442, 2003.

73. Maries, E., Kordower, J.H., Chu, Y., Collier, T.J., Sortwell, C.E., Olaru, E., et al. Focal not widespread grafts induce novel dyskinetic behavior in parkinsonian rats. Neurobiol Dis 21, 165, 2006.

74. Tamariz, E., Wan, A.C.A, Pek, Y.S., Giordano, M., Hernández-Padrón, G., Varela-Echavarría, A., et al. Delivery of chemotropic proteins and improvement of dopaminergic neuron outgrowth through a thixotropic hybrid nano-gel. J Mater Sci Mater Med 22, 2097, 2011.

75. Yang, W., Hu, J., Uemura, A., Tetzlaff, F., Augustin, H.G., and Fischer, A. Semaphorin-3 C signals through Neuropilin-1 and PlexinD 1 receptors to inhibit pathological angiogenesis. EMBO Mol Med 7, 1267, 2015.

Address correspondence to: Iván Velasco, PhD

Instituto de Fisiología Celular-Neurociencias Universidad Nacional Autónoma de México México D.F.-04510

México

E-mail: ivelasco@ifc.unam.mx

Received: January 8, 2016

Accepted: May 12, 2016

Online Publication Date: June 1, 2016 